\title{
Detection of bovine viral diarrhoea virus antigen and RNA in oviduct and granulosa cells of persistently infected cattle
}

\author{
P. J. Booth*, D. A. Stevens, M. E. Collins and J. Brownlie \\ Institute for Animal Health, Compton, Newbury, Berkshire, RG16 ONN, UK
}

\begin{abstract}
Large-scale in vitro bovine embryo production systems commonly use genital tracts obtained from an abattoir as a source of both cumulus-oocyte complexes and co-culture feeder cells. Tissues derived from this source may be contaminated with non-cytopathogenic bovine viral diarrhoea virus (BVDV) since, in several countries surveyed, approximately $1 \%$ of animals tested are persistently infected with this pathogen. Therefore, the use of such material in in vitro fertilization systems presents a potential risk for the transmission of BVDV to bovine embryos and via embryo transfer. This potential was investigated by obtaining oviduct epithelial cells and granulosa cells, which are commonly used as feeder cells, from cattle persistently infected with BVDV and examining them for the presence of BVD viral antigen (p80 non-structural protein and gp53 envelope glycoprotein) by indirect immunofluorescent histochemistry, and also viral RNA (encoding the $\mathrm{p} 80$ region) by in situ hybridization. In addition, titres of virus present in oviduct, ovary and blood were assayed by immunodetection on calf testis cell cultures. Luminal epithelial cells from the oviduct and primary cultures of granulosa cells and oviduct epithelial cells from such cattle were shown to contain both viral antigen and RNA. The susceptibility of both cell types to BVDV infection was further established by inoculating primary cell cultures of cells derived from cattle not infected with BVDV with a cloned isolate of non-cytopathogenic BVDV (Pe515). RNA encoding BVDV and the antigen were detected $12 \mathrm{~h}$ after inoculation. Viral titres present in oviduct, ovary and blood were between $\geq 10^{2.2}$ and $10^{7} ; \geq 10^{2.2}$ and $10^{6.75}$; and $10^{3.5}$ and $10^{4.25}$ tissue culture infective doses, (TCID) $)_{50} \mathrm{~g}^{-1}$, respectively. Control tissues from cattle not infected with BVDV, tested in each of the preceding techniques, were negative. These data establish that ovary and oviduct of persistently infected animals harbour non-cytopathogenic BVDV and that granulosa cells and oviduct epithelial cells, which are used as co-culture cells during bovine embryonic development in vitro and which, in the case of granulosa cells, constitute the cumulus investment surrounding the oocyte, are a vehicle for the potential transmission of BVDV to developing embryos.
\end{abstract}

\section{Introduction}

Recommendations have been published by the Office International Des Epizooties (Singh, 1985) and the International Embryo Transfer Society (IETS, 1990) detailing sanitary procedures required for bovine embryo transfer to prevent transmission of infectious agents. These measures include health certification of donor cattle, implementation of recommended washing procedures, removal of adherent debris and rejection of embryos with damaged zonae pellucidae. In addition, the microbial status of embryo flush and transfer fluids has also received attention, particularly bovine serum, which is routinely incorporated into these solutions and cell culture media. Such sera, and indeed bovine tissues, may be infected with bovine viral diarrhoea virus (BVDV), which has been

\footnotetext{
*Correspondence and reprints: INRA, Station de Physiologie de la Reproduction des Mammifères Domestiques, Centre de Tours, 37380 Nouzilly, Tours, France.

Received 18 January 1995
}

recognized as a potential contaminant of cell cultures (Nuttal et al., 1977; Rossi et al., 1980). Less attention has been paid to the use of oviduct epithelial cells (OECs) and granulosa cells (GCs) as co-culture cells during production in vitro of bovine embryos, which generate a supplementary potential source of infection, particularly as these cells are commonly derived from abattoirs and are of unknown health status.

The literature suggests that, provided sanitary guidelines are implemented, the risk of transmission of bovine viruses by embryo transfer is extremely small. However, not all infectious bovine viral agents have been studied with respect to germline transmission, or the research has been limited or inconclusive (IETS, 1990, 1992), and there is still speculation concerning the potential transmission of BVDV by embryo transfer.

The BVD virus exists as two biotypes of different cytopathogenicity, distinguished by their effect in cell culture (Brownlie, 1985). Preliminary studies indicated that the cytopathogenic variant cannot infect embryos in vitro (although a potential contradiction to these data was presented Downloaded from Bioscientifica.com at 04/26/2023 07:17:14AM 
by Archbald et al., 1979), and cannot be transmitted by embryo transfer (Singh et al., 1982; Potter et al., 1984; Bielanski and Hare, 1988). Furthermore, this biotype cannot establish a persistent infection in the early fetus (Brownlie et al., 1989). In contrast, inoculation in utero of the noncytopathogenic variant may precipitate an immunotolerant persistent condition (McClurkin et al., 1984), thus demonstrating a clear difference in fetal pathogenicity between the two biotypes. The noncytopathogenic virus is evidently capable of vertical transmission (Straver et al., 1983; Radostits and Littlejohns, 1988), but the earliest stage of development in vivo at which viral infection of the oocyte or embryo can occur has not been described. Brock and Stringfellow (1993) reported that viral antigen can be expressed in blastocysts as early as day 14 after hatching after infection in vitro. In the absence of evidence to suggest that the zona pellucida is a barrier to the noncytopathogenic biotype, concern that prehatched transferable embryos are susceptible to viral infection is justified. Two reports (Bak et al., 1992; Wentink et al., 1991) that three non-viraemic calves were born after embryo transfer from donors that are persistently infected with BVDV are insufficient evidence to conclude that the risk of transmission is negligible. Until prehatched bovine embryos are shown to be resistant to the non-cytopathogenic virus, procedures to eliminate BVDV contamination during IVF and embryo transfer protocols should be implemented.

The intention of this study was to investigate whether granulosa and oviduct epithelial cells used as co-culture cells in IVF protocols and embryo transfer procedures are susceptible to infection by non-cytopathogenic BVDV, and therefore act as vehicles for the potential transmission of this agent to bovine embryos.

\section{Materials and Methods}

\section{Animals, tissue preparation and cell culture}

Six persistently infected animals were acquired from the Institute for Animal Health (Compton) and the University of Liverpool, namely, 1280 (7 weeks old, Friesian), NF5349 (18 months old, Aberdeen Angus), S2HS (23 months old, Friesian heifer), LL (16 months old, Aberdeen Angus), LS (11 months old, Aberdeen Angus) and DP197 (19 months old, Friesian heifer, 120 days pregnant). Control animals, which were free from BVD virus (as determined by virus isolation techniques on whole blood samples) were also acquired.

Ovaries, oviducts and EDTA-treated blood samples were collected after death. Tissues that were used immediately from the laboratory abattoir were stored in $0.01 \mathrm{~mol} \mathrm{PBS} \mathrm{l}^{-1}$ (pH 7.2) while those transported $(<4 \mathrm{~h})$ were collected in medium E199 (plus Earle's salts and bicarbonate; Sigma, St Louis, MO) containing $50 \mathrm{iu}$ penicillin $\mathrm{G} \mathrm{ml}^{-1}$ (Sigma) and $0.05 \mathrm{mg}$ streptomycin $\mathrm{ml}^{-1}$ (Sigma) and stored between 20 and $37^{\circ} \mathrm{C}$. Cryoblocks of oviduct were prepared in OCT embedding medium (Miles Inc., Elkhart). Oviduct segments destined for in situ hybridization were fixed in neutral buffered formalin and embedded in paraffin wax, as described by Desport et al. (1992). Further sections of oviduct were frozen at $-70^{\circ} \mathrm{C}$ for virus titration. Ovarian follicles were aspirated by syringe to recover follicular fluid containing granulosa cells. Follicular fluid was centrifuged ( $175 \mathrm{~g}, 5 \mathrm{~min}$ ) and the cell pellet was washed twice in $5 \mathrm{ml}$ tissue culture medium (TCM; medium E199 plus Earle's salts and bicarbonate containing 50 iu penicillin $\mathrm{G} \mathrm{ml}^{-1}, 0.05 \mathrm{mg}^{-1}$ streptomycin $\mathrm{ml}^{-1}, 4 \mathrm{mmol}$ glutamine $\mathrm{l}^{-1}, 0.2 \mathrm{mmol}$ pyruvate $\mathrm{l}^{-1}, 20.9 \mathrm{mmol}$ lactate $\mathrm{l}^{-1}$ (Sigma)) and 10\% (v/v) oestrous cow serum (Institute for Animal Health farm). The serum was negative for both BVD virus and antibody. Cells were finally resuspended in TCM and seeded into culture flasks (Becton Dickinson, Bedford, MA) or six-well plates (Nunc, Roskilde) containing glass coverslips and incubated at $37^{\circ} \mathrm{C}$ in $5 \% \mathrm{CO}_{2}$ in air.

OECs were recovered from the remaining sections of oviduct by the method of Eyestone and First (1989) with minor modifications. Briefly, mesenteric tissue was dissected from the oviduct and washed in $70 \%(\mathrm{v} / \mathrm{v})$ ethanol and blotted dry. Epithelial cells were extruded by squeezing along the length of each oviduct with forceps. Cells were disaggregated by repetitive aspiration with a pipette and then washed and seeded into culture vessels as detailed for granulosa cells.

Calf testis cell ( $\mathrm{CTe}$ ) fibroblasts were derived from $<5$-dayold animals and prepared according to a standard primary culture technique (Freshney, 1987).

The susceptibility of OECs, GCs and CTe cells to infection with BVDV in vitro was also investigated. Confluent primary cell cultures derived from animals not infected with BVDV were inoculated with a non-cytopathogenic strain of BVDV (Pe515; $1 \times 10^{4}$ tissue culture infective dose (TCID) $)_{50} \mathrm{ml}^{-1}$ ) at a multiplicity of infection of approximately one. Initially, the inoculum was added for $2 \mathrm{~h}$ in a limited volume to facilitate viral adsorption. The cultures were terminated at 3, 6, 9, 12, $24 \mathrm{~h}$ and 3 days after infection.

Coverslip cultures of GCs and OECs for immunofluorescent staining were fixed in acetone. GCs and OECs cultured in flasks and destined for staining by in situ hybridization were cytospun $(400 \mathrm{~g}, 7 \mathrm{~min})$ onto slides coated with aminopropyltriethoxysilane and fixed in acetone. Before cytospinning, GCs were resuspended in TCM by a standard trypsinization method (Freshney, 1987), whereas OECs were resuspended using a cell scraper.

\section{Virus isolation and enzyme-linked immunosorbent assay}

Tissue samples $(0.1-0.2 \mathrm{~g})$ destined for viral titration were ground to a paste in a mortar and pestle using sterile sand. CTe medium was added to achieve a $10 \%(\mathrm{w} / \mathrm{v})$ suspension, which was centrifuged $(700 \mathrm{~g}, 5 \mathrm{~min})$ to provide a supernatant fluid suitable for inoculation.

CTe cultures of passage 3-8 were grown on coverslips in six-well plates or test tubes in CTe Medium. The latter comprised Eagle's basal medium (Modified; ICN Flow Biomedicals, Thame) containing $8.2 \%(\mathrm{v} / \mathrm{v})$ fetal calf serum (Gibco, Paisley), $2.34 \mathrm{mg}$ lactalbumin $\mathrm{ml}^{-1}, 2 \mathrm{mmol}$ L-glutamine $\mathrm{I}^{-1}$, $1.05 \mathrm{mg}$ sodium bicarbonate $\mathrm{ml}^{-1}, 100 \mathrm{U}$ penicillin $\mathrm{ml}^{-1}$,

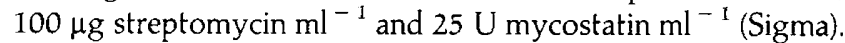

Viral adsorption was permitted by adding inocula to wells or test tubes containing a reduced volume of medium, to maximize viral adherence to CTe monolayers. After incubating for $1.5-2.0 \mathrm{~h}$, inocula that were potentially toxic were decanted Downloaded from Bioscientifica.com at 04/26/2023 07:17:14AM via free access 
and the volumes of the vessels were readjusted with $\mathrm{CTe}$ medium. The cells were incubated at $38.5^{\circ} \mathrm{C}$ in $5 \% \mathrm{CO}_{2}$ in air for 7 days and BVDV was detected by immunofluorescent staining. This technique was used to determine viral titres in oviduct, ovary and blood.

The ELISA was based on a method developed by Voller and Bidwell (1976) and adapted by Howard et al. (1985) with minor modifications.

\section{Immunofluorescent staining}

Cryosections (8-10 $\mu \mathrm{m}$ thick) were cut onto slides coated with 3-aminopropyltriethoxysilane (Sigma) and fixed in acetone. Sections were stained by an indirect immunofluorescent technique. Briefly, preparations were incubated with 1:20 normal swine serum (Gibco), and then the monoclonal antibody, and subsequently goat anti-mouse immunoglobulin conjugated to fluorescein isothiocyanate (FITC; Southern Biotechnology Associates Inc., Birmingham, AL). Preparations were mounted in $80 \%(\mathrm{v} / \mathrm{v})$ glycerol containing $2.5 \%(\mathrm{w} / \mathrm{v})$ 1,4-diazabicyclo-[2.2.2]octane (DABCO; Sigma). Reagents for an alternative staining protocol were sheep anti-mouse $I g G$ conjugated to biotin (Serotec, Slough), and then streptavidinFITC conjugate (Amersham International, Amersham). All reagents were diluted in 1:20 normal swine serum to reduce nonspecific binding. The immunofluorescent staining technique was performed on cryosections of oviduct and coverslip cultures of GCs, OECs and CTe cells.

Anti-BVDV monoclonal antibodies were specific to the nonstructural p80 protein of BVDV (antibodies: WBI12, WB103) and to the viral envelope glycoprotein gp53 (antibody WB162). The immunoglobulin isotypes of the antibodies were: WB103, WB162; IgG1: WB112; IgG2a. The specificity of immunofluorescent staining was established using monoclonal antibodies to respiratory syncytial virus (RSV) of identical isotype (RSV22, IgG2a: RSV32, IgG1) to that of the BVDV antibodies. Nonspecific staining reactions were also detected by including a mouse anti-chicken monoclonal antibody (AVII; specific to a surface marker of mature chicken white blood cells) with every test. Specific binding of the conjugates was tested by substitution of the BVDV antibodies or sheep anti-mouse biotin reagent with normal swine serum. Each of the above tests for specificity was performed on potentially infected and noninfected control tissue.

\section{In situ hybridization}

The detection of RNA encoding BVDV in cytospun cell preparations and on oviduct formalin-fixed, paraffin-wax embedded histosections by in situ hybridization was performed using a digoxigenin-labelled riboprobe as described by Desport et al. (1992). Briefly, the 758 base riboprobe was derived from a highly conserved region of the BVDV genome encoding a portion of p80 (Collett et al., 1989). After hybridization, the bound probe was detected by incubating with sheep antidigoxigenin Fab fragments conjugated to alkaline phosphatase (Boehringer Mannheim, Mannheim). This preceded a colour reaction involving substrate NBT/BCIP (Promega, Southampton). The specificity of hybridization was investi-
Table 1. Titres of non-cytopathogenic BVDV in tissues and blood from persistently infected cattle $\left(\log _{10}\right.$ TCID $\left._{50} \mathrm{~g}^{-1}\right)$

\begin{tabular}{lccc}
\hline & \multicolumn{3}{c}{ Titre $\left(\log _{10} \mathrm{TCID}_{50} \mathrm{~g}^{-1}\right)$} \\
\cline { 2 - 4 } Animal & Ovary & Oviduct & Blood \\
\hline \multirow{2}{*}{1280} & $\mathrm{NT}$ & 7.0 & $3.2^{+}$ \\
NF & 4.7 & 5.7 & 3.7 \\
S2HS & $\geq 2.2^{*}$ & $\geq 2.2^{*}$ & 3.5 \\
LL & 5.5 & 4.5 & 3.5 \\
LS & 5.0 & $\geq 3.5$ & 4.0 \\
DP & 6.75 & 6.0 & 4.25 \\
\hline
\end{tabular}

NT: not tested.

*Virus isolation only: sample not titrated.

${ }^{+}$Sample collected I day after birth. Maternal antibodies in colostrum may have reduced blood viral titre of calf.

TCID: tissue culture infective dose.

gated using GCs and OECs from animals not infected with BVDV and by substituting a riboprobe for a neomycin resistance gene (Boehringer Mannheim) for the BVDV riboprobe. The in situ hybridization technique was performed on both GCs, OECs and oviduct tissue sections acquired from animals S2HS and LS, and also on single samples of OECs and GCs obtained from animals not infected with BVDV that had been inoculated with the non-cytopathogenic virus (Pe515) in vitro.

\section{Results}

\section{Isolation of BVDV and antigen detection}

Conventional virus isolation techniques established the presence of BVDV in every blood sample and ovarian and oviductal tissue sample obtained from persistently infected animals (Table 1). Among animals, titres of virus measured in ovary and oviduct varied 100-fold. Within animals, the viral titres recorded in these same tissues were, in samples that had been completely titrated, in excess of those observed in corresponding blood samples.

BVDV antigen, detected by immunofluorescent staining, was present in epithelial cells of oviduct cryosections of all the persistently infected animals investigated. The magnitude of the fluorescent staining in the cells of the epithelia ranged from very intense to an absence of labelling. Staining was also evident in the lamina propria (Fig. Ia), the inner and outer muscularis, the tunica media of blood vessels and the serosa. The serosa and lamina propria generally produced weaker staining than did other areas and were occasionally negative. Similarly, coverslip primary cultures of GCs (Fig. 1e) and OECs (Fig. Ic) derived from five persistently infected cattle and stained by immunocytochemistry exhibited fluorescence ranging among animals from intense to weak (Table 2). Immunofluorescence was also observed in primary cell cultures of GCs (Fig. If) and OECs (Fig. 1d) derived from BVDV-negative animals infected in vitro with the Pe515 strain of virus. In both these cell types, antigen was weakly detected in isolated cells Downloaded from Bioscientifica.com at 04/26/2023 07:17:14AM 
or two-cell foci by $12 \mathrm{~h}$ after infection. Staining was restricted to foci of $\mathrm{I}-4$ cells at $24 \mathrm{~h}$ after infection $(<1 \%$ total cells stained). By 48 h and 3 days after infection approximately $10 \%$ and $50 \%$, respectively, of OECs exhibited immunofluorescent staining. In comparison to OECs, the proportion of GCs expressing detectable antigen was greater at both $24 \mathrm{~h}$ (approximately $1 \%$ total cells staincd) and $48 \mathrm{~h}$ after infection (approximately $90 \%$ stained). The standard CTe cell line used for BVDV culture in this investigation displayed very weak fluorescent staining as early as $3 \mathrm{~h}$ after infection in widely scattered individual cells. Intense staining was present in approximately $1 \%$ of CTe cells at $9 \mathrm{~h}$ after infection and increased to approximately $10 \%$ and $90 \%$ by 12 and 24 h after infection, respectively.

The intensities of BVDV-specific immunofluorescence on coverslip cultures and cryosections varied both between animals and monoclonal antibodics, and ranged from undetectable to intense (Table 2). Variations in the immunoreactivities of the pancl of BVDV monoclonal antibodies used, in relation to the field strain of BVDV present, were evident by the absence of labelling in all tissues tested from animal DP 197 after immunohistochemistry using antibody WBI62. The remaining antibodies all produced immunofluorescent signals in tissues of this animal, and all three BVDV antibodies tested produced
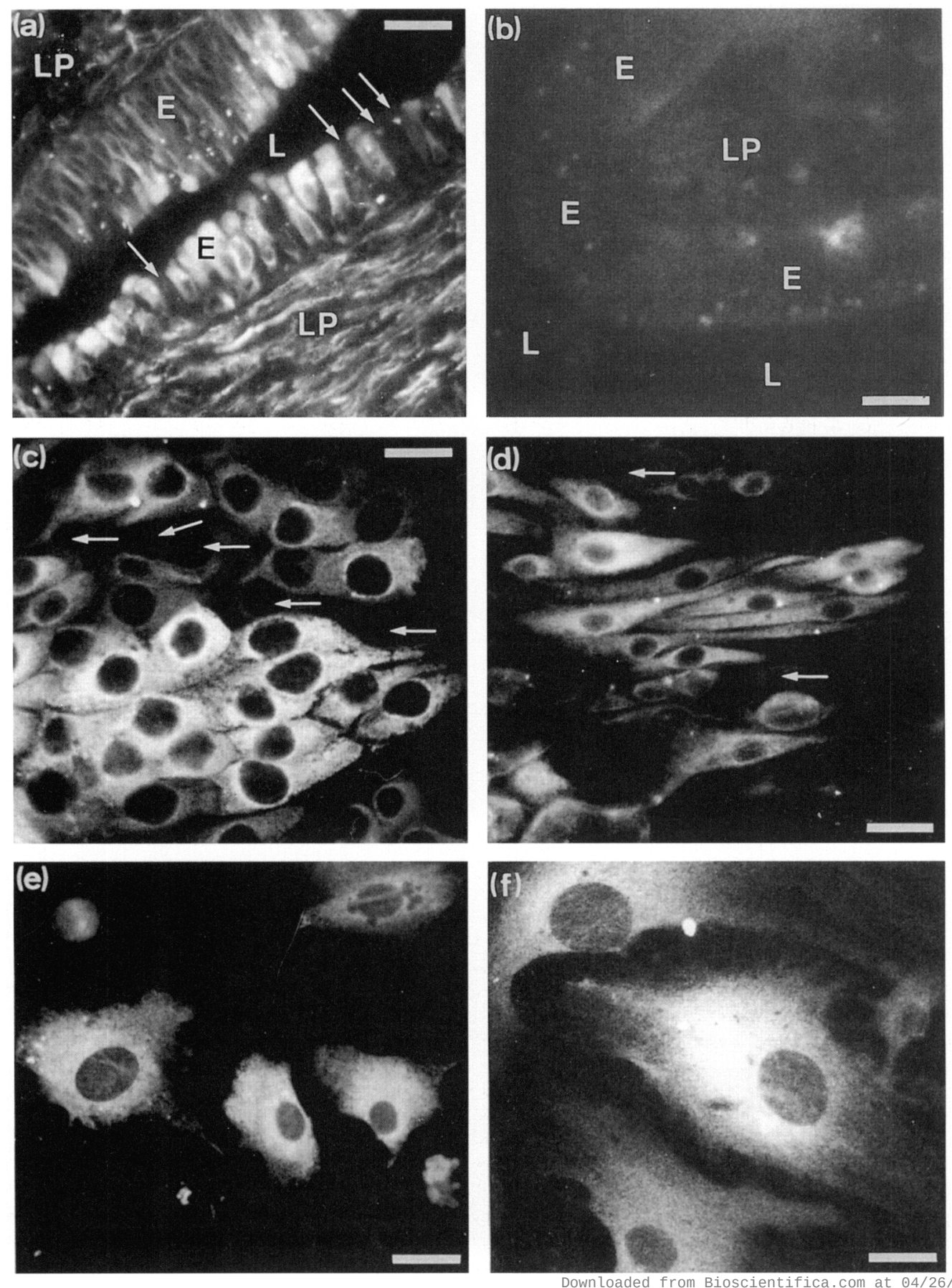
Table 2. Detection of viral antigen in primary cultures of oviduct epithelial and granulosa cells by immunofluorescence

\begin{tabular}{|c|c|c|c|c|c|c|}
\hline & \multicolumn{3}{|c|}{ Oviduct epithelial cells } & \multicolumn{3}{|c|}{ Granulosa cells } \\
\hline & \multicolumn{6}{|c|}{ Antibody } \\
\hline & WBI12 & WB103 & WB162 & WB112 & WB103 & WBI62 \\
\hline \multicolumn{7}{|l|}{ Animal ${ }^{*}$} \\
\hline NF5349 & $*$ & $*$ & $*$ & ++ & ++ & ++ \\
\hline S2HS & ++ & +++ & + & $\S$ & $s$ & $\S$ \\
\hline LL & ++ & ++ & ++ & ++ & ++ & ++ \\
\hline LS & +++ & NT & $+t+$ & ++ & ++ & +++ \\
\hline DP197 & +++ & NT & - & + & + & - \\
\hline
\end{tabular}

\footnotetext{
+++ Intense staining; ++ moderate staining; + weak staining; - no staining; NT: not tested.

*Intense cellular autofluorescence masked immunofluorescence.

${ }^{5}$ Not tested: bacterial infection of primary cell culture.

${ }^{\ddagger}$ No data available for animal 1280 .
}

immunostaining in tissues of all other BVDV-infected animals investigated.

Immunofluorescence was not observed in every cell of either cryosections or coverslip cultures. When present, staining was cytoplasmic and not in the nucleus, a cellular distribution characteristic of this RNA virus. The specificity of the immunocytological staining was investigated by standard techniques. Immunofluorescence greater than nonspecific background intensity was absent when coverslip primary cell cultures and tissue sections derived from BVD virus-free animals were incubated with the BVDV-specific monoclonal antibodies (Fig. Ib). Substitution of BVDV-specific antibodies with control antibodies specific to bovine respiratory syncytial virus antigens (RSV22, RSV32) and to a chicken lymphocyte surface marker (AV1I), which were of identical immunoglobulin isotypes to the BVDV monoclonals, all produced no visible immunoreactivity greater than the normal faint background intensity in tissues derived from BVDV-infected animals. The specificity of the fluorescein isothiocyanate-labelled secondary antibody was shown by the absence of immunofluorescence in BVDV-infected tissues incubated with the conjugate alone.

\section{Detection of $m R N A$ encoding BVDV}

An intense positive hybridization signal for RNA encoding BVDV was observed in the epithelial cells of oviduct cryosections prepared from BVDV-infected cattle (Fig. 2a). Within this tissue, staining was also detected in cells of the lamina propria. Primary cultures of OECs (Fig. 2c,d) and GCs (Fig. $2 f, g$ ) acquired from BVDV-infected animal LS and subjected to cytocentrifugation preceding the in situ hybridization protocol also revealed the presence of mRNA encoding BVDV, which is characterized by blue staining in isolated cells and groups of cells. Oviduct epithelial cells (Fig. 2e) and granulosa cells cultured from control animals not infected with BVDV and inoculated in vitro with BVDV strain Pe515 presented a strong signal to in situ hybridization. A characteristic cytoplasmic pattern of staining was recorded, supporting the results of the immunofluorescence staining. In some cells, the differential staining pattern was obscured by intense cytoplasmic labelling (Fig. 2c,e,f). Again, only a proportion of the cells on each slide showed positive staining for viral RNA, indicating that not all of the cells in the source material, or after infection in vitro, harboured BVDV. Furthermore, the intensity of the

Fig. 1. Detection of bovine viral diarrhoea virus (BVDV) antigens in oviduct cryosections and primary cultures of oviduct epithelial cells by indirect immunofluorescent histochemistry. Arrows indicate the location of nuclei of nonimmunoreactive cells in (c) and (d). The scale bars represent $50 \mu \mathrm{m}$. (a) Oviduct cryosection from a BVDV-infected animal (LL) immunostained with monoclonal antibody WB112 (specific to BVDV nonstructural protein $\mathrm{p} 80$ ). Cells of the epithelial layer $(\mathrm{E})$ exhibited immunofluorescence ranging from very intense to an absence of signal (indicated by arrows). Within BVDV-immunoreactive epithelial cells, nonstaining basally located nuclei can be observed. BVDV antigen was not detected within the oviductal lumen (L). Cells within the lamina propria (LP) exhibited immunoreactivity, which in the lower mucosal fold is quite intense. (b) The tip of one mucosal fold of an oviductal cryosection from a control animal that was not infected with BVDV (H232) immunostained with the same monoclonal antibody as in (a). This print has been overexposed deliberately to increase the limited histological detail present. No BVDV-specific immunoreactivity is evident. (c) Primary culture of oviduct epithelial cells derived from a BVDV-infected animal (S2HS) and incubated with monoclonal antibody WB112. Variation in the intensity of cytoplasmic staining is observed between cells. Staining, when present, is strictly cytoplasmic and non-nuclear. (d) Primary culture of oviduct epithelial cells derived from a control animal that was not infected with BVDV (HD393) $96 \mathrm{~h}$ after inoculation in vitro with non-cytopathogenic BVDV (Pe515), stained with monoclonal antibody WB162 (specific to the BVDV envelope glycoprotein gp53). (e) Primary culture of granulosa cells from a BVDV-infected animal (NF5349) stained with antibody WB162. (f) Primary culture of granulosa cells derived from an animal that was not infected with BVDV (H8296), which had been inoculated in vitro with BVDV. The culture was terminated $48 \mathrm{~h}$ after inoculation and stained with antibody WB103 (specific to the BVDV p80 nonstructural protein). 

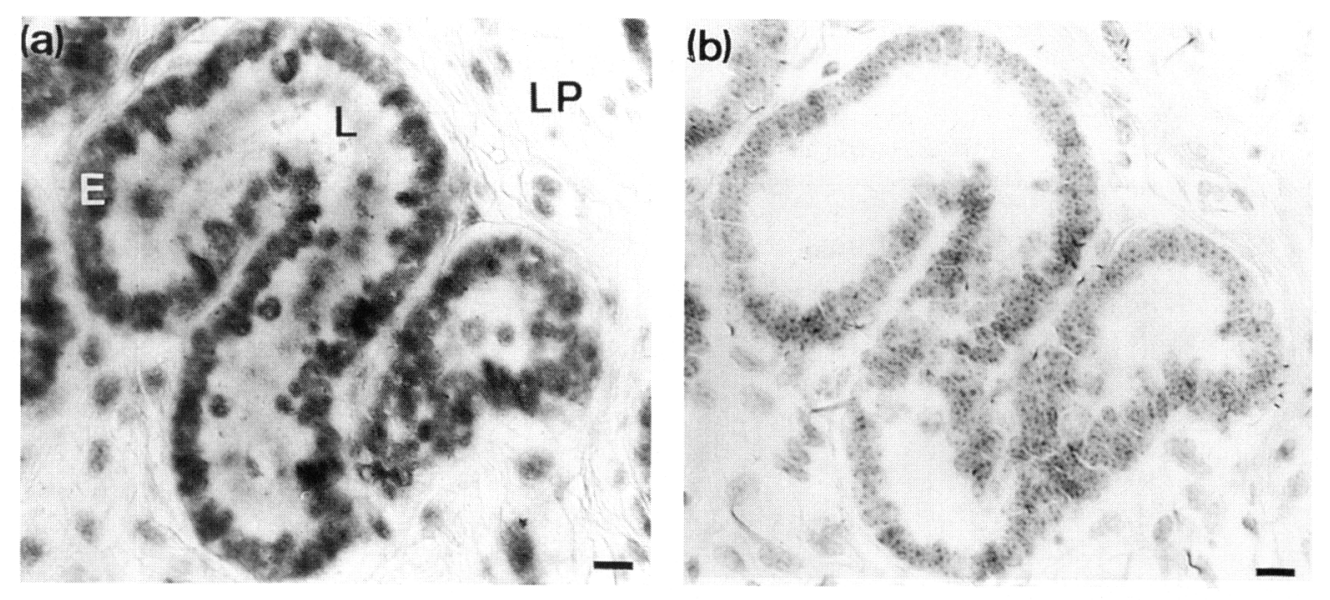
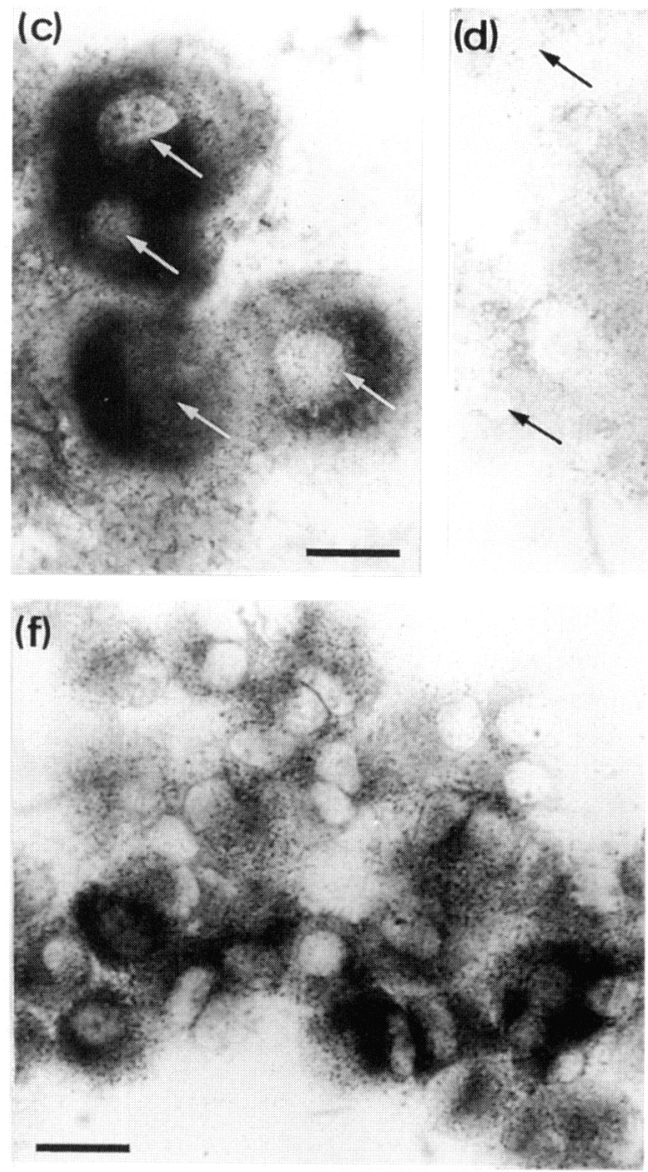

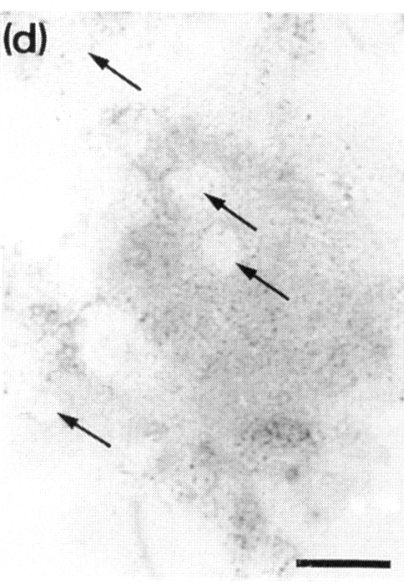

(g)
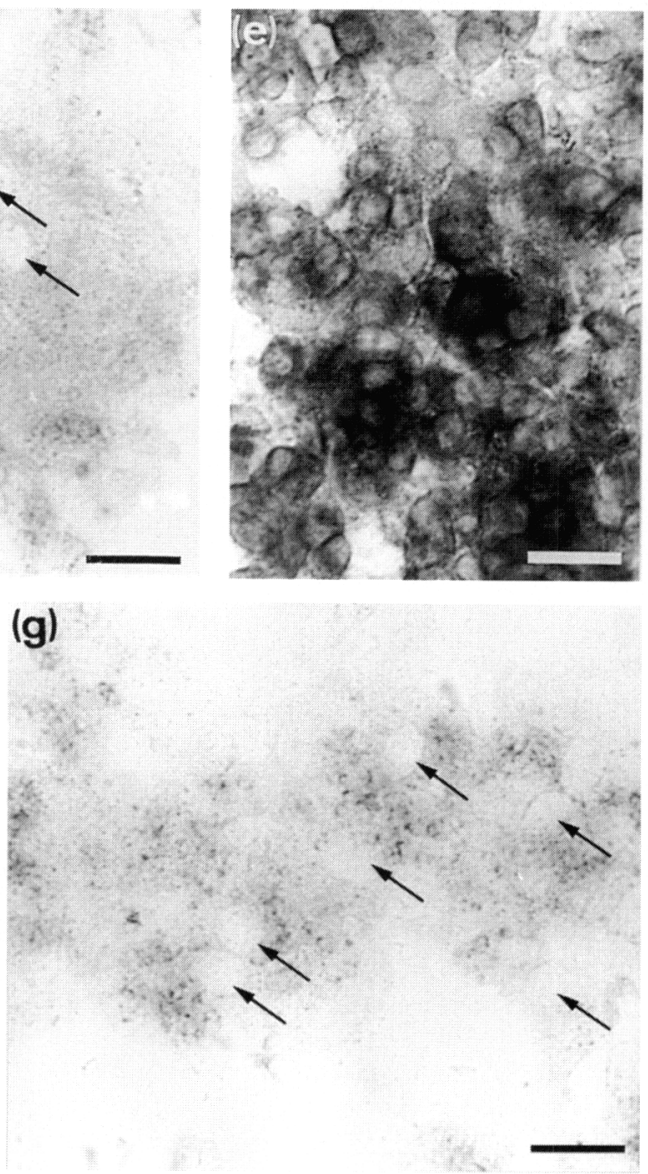

Fig. 2. Detection of mRNA encoding bovine viral diarrhoea virus (BVDV) in oviduct sections and in cytocentrifuged cell preparations of oviductal epithelial (OEC) and granulosa cells (GCs) by in situ hybridization. The scale bars represent $50 \mu \mathrm{m}$. Arrows indicate the location of some cell nuclei in $(c, d$ and g). (a) In situ hybridization, using the BVDV riboprobe, on a histological section of an oviduct taken from a BVDV-infected animal. Intense staining is present within the epithelial layer (E) and also within isolated cells of the lamina propria (LP). Staining that is apparently present within the oviduct lumen (L) is that on epithelial cells of neighbouring mucosal tissue. (b) Adjacent serial section to that shown in panel (a), demonstrating the nonspecific background hybridization signal when using the control neomycin resistance probe at an equal concentration to that of the BVDV riboprobe. (c) Cytocentrifuged cell preparation of a primary culture of OECs from a persistently BVDV-infected animal (LS) hybridized with the BVDV specific riboprobe. (d) A similarly cytospun OEC preparation to that shown in (c), demonstrating nonspecific background staining using the neomycin resistance probe. (e) Hybridization of the BVDV riboprobe to cytocentrifuged samples of OECs derived from a BVDV-free animal and infected in vitro with strain Pe515. (f) A cytospun sample from a primary culture of GCs derived from a BVDV-infected animal, demonstrating the presence of viral RNA using the BVDV-specific riboprobe. (g) Nonspecific hybridizationdsignab generated usingathenneomycin/2023 $07: 17: 14 \mathrm{AM}$ resistance probe on a similar cell preparation to that detailed in panel ( $\mathrm{f}$ ). 
hybridization signal varied between cells and ranged from weak to very prominent staining (Fig. $2 \mathrm{c}, \mathrm{e}, \mathrm{f}$ ).

The conditions used for the in situ hybridization were physically harsh and in many cases a high degree of cell loss was observed from cytospun preparations. The use of slides coated with 3-aminopropyltriethoxysilane remedied this to some degree, but care had to be exercised at all stages of the hybridization and detection procedures. It was important to control for nonspecific staining of cells, as the reporter enzyme, alkaline phosphatase, is widely distributed in biological material and is physically robust. This was achieved in several ways, but initially by the addition of enzyme substrate solution to cells that had been subjected to identical reaction conditions but to which no riboprobe had been hybridized. These control results were negative under the conditions used. This finding is important, as alterations in the fixation or hybridization conditions could lead to a failure to quench endogenous alkaline phosphatase enzymes, resulting in false positive reactions. Staining was not generated using the neomycin resistance probe on BVDV-infected cell samples (Fig. 2b,d,g) nor observed in samples derived from animals that were not infected with BVDV hybridized with either riboprobe.

\section{Discussion}

The diagnostic techniques applied in this investigation have established that GCs and OECs are susceptible to infection by the non-cytopathogenic biotype of BVDV. These data add to information concerning the pathogenesis of this virus in the reproductive tract of cows and have important implications for IVF and embryo transfer programmes in terms of the potential transmission of this pathogen. The detection of noncytopathogenic BVDV in the epithelial tissues of the oviduct and ovary supplements the evidence that epithelial cells in general, together with the central nervous system and lymphoid tissues, are predeliction sites for this virus (Ohmann et al., 1981; Ohmann, 1983; Allan et al., 1989; Desport et al., 1992). Tissues underlying epithelial layers may also be infected in gastrointestinal and reproductive tissues (Ohmann, 1983; Kirkland et al., 1991) and, as described here, in the propria and vascular system of the oviduct. The tropism of this virus for granulosa and oviductal epithelia has not previously been documented, although the cytopathogenic variant has been isolated from both ovarian (Ssentongo et al., 1980) and oviductal tissue (Archbald et al., 1973) after acute infection. The present study indicates that these organs can also harbour the non-cytopathogenic virus and that these tissues are highly permissive for BVDV replication, as they contain viral titres in excess of those recorded in the blood in persistently infected animals. The titres of virus present may rise to $10^{7} \mathrm{TCID}_{50}$ $\mathrm{g}^{-1}$, which is in agreement with titres recorded in persistently infected animals (Meyling, 1984; Clarke et al., 1987).

Contamination with non-cytopathogenic BVDV at any stage during the handling of bovine oocytes or embryos in vitro could permit the transmission of the virus. Previous consideration of this topic has focused attention on contamination of fetal bovine serum with non-cytopathogenic BVDV (Nuttal et al., 1977; Rossi et al., 1980). Rossi et al. (1980) reported that $63 \%$ ( 13 of 21 ) of commercial nonirradiated sera were BVDV-positive. As cell lines derived from persistently infected animals are likely to be similarly contaminated (Nuttal et al., 1977; Rossi et al., 1980), the use of co-culture cells obtained from ovaries from cows of unknown health status from abattoirs is a cause for concern. The virus has been isolated from degenerate ova that had been fertilized and co-cultured in the presence of oviduct cells previously infected with BVDV (Zurovac et al., 1994). At an earlier stage of development in vitro, whole batches of cumulus-oocyte complexes may be infected if tissues from persistently infected animals are used. Considering the large number of ovaries acquired from abattoirs by commercial companies engaged in embryo generation, and the evidence that approximately $1 \%$ of animals in an abattoir may be infected (Howard et al, 1986, and references therein), contamination of culture systems by BVDV is not an unlikely event. Avery et al. (1993) reported that $12 \%$ of their in vitro embryo production system experiments were contaminated with BVDV, and BVD virus was isolated from $1.2 \%$ of oviduct cell samples tested and destined for use during culture in vitro (Bielanski et al., 1993).

The capacity of non-cytopathogenic BVDV to infect the cells of the prehatched embryo or to adhere to the zona pellucida still remains unresolved. Certainly after hatching, viral antigen can be expressed in embryos at day 14 after exposure to the non-cytopathogenic biotype in vitro (Brock and Stringfellow, 1993). If BVDV infection is permissible in trophectoderm or inner cell mass cells after hatching, such cells may even be susceptible in blastocysts during prehatching development (the time at which embryos are transferred to recipients) if the virus can penetrate the zona pellucida. An undamaged zona pellucida may present a barrier to viral penetration of the oocyte or embryo, but may be liable to being breached at specific stages of development or under certain conditions. This could occur during or after fertilization, perhaps facilitated by the penetration tract of the spermatozoon through the zona (Guerin et al., 1992) or subsequent to damage and cracking of the zona during cryopreservation (Rall and Meyer, 1989) or as a consequence of micromanipulation procedures.

Until it has been proved unequivocally that the bovine embryo is not susceptible to infection by non-cytopathogenic BVDV or it has been shown that adherent virus can be removed by washing techniques, commercial companies producing embryos generated in vitro, and those engaged in embryo transfer, are recommended to screen for the presence of this virus.

This work was jointly funded by the Milk Marketing Board and the Meat and Livestock Commission. The authors thank W. Christie (Genus) and R. Murray (University of Liverpool) for the provision of some persistently infected animals. Provision of technical advice from, and performance of viral titrations by M. C. Clarke are greatly appreciated. The monoclonal antibodies were a generous gift from S. Edwards, Central Veterinary Laboratory, Weybridge.

\section{References}

Allan GM, McNulty MS, Bryson D, Mackie D and Platten M (1989) Demonstration of bovine virus diarrhoea virus antigen in formalin-fixed, paraffin embedded tissue using a streptavidin/biotin technique Research in Veterinary Science $46416-418$

Downloaded from Bioscientifica.com at 04/26/2023 07:17:14AM 
Archbald LF, Gibson CD, Schultz RH, Fahning ML and Zemjanis R (1973) Effects of intrauterine inoculation of bovine viral diarrhea-mucosal disease virus on uterine tubes and uterus of nonpregnant cows American Journal of Veterinary Research 34 1133-1137

Archbald LF, Fulton RW, Seger CL, Al-bagdadi F and Godke RA (1979) Effect of the bovine viral diarrhea (BVD) virus on preimplantation bovine embryos: a preliminary study Theriogenology 11 81-89

Avery B, Greve T, Ronsholt L and Botner A (1993) Virus screening of a bovine in vitro embryo production system Veterinary Record 132660

Bak A, Callesen H, Meyling A and Greve T (1992) Calves born after embryo transfer from donors persistently infected with BVD virus Veterinary Record 13137

Bielanski A and Hare WCD (1988) Effect in oitro of bovine viral diarrhea virus on bovine embryos with the zona pellucida intact, damaged and removed Veterinary Research Communications 12 19-24

Bielanski A, Loewan KS, Del Campo MR, Sirard MA and Willadsen S (1993) Isolation of bovine herpesvirus-I (BHV-1) and bovine viral diarrhea virus (BVDV) in association with the in vitro production of bovine embryos Theriogenology 40 531-538

Brock KV and Stringfellow D (1993) Comparative effects of cytopathic and noncytopathogenic bovine viral diarrhea virus on bovine blastocysts Theriogenology 39196

Brownlie J (1985) Clinical aspects of the bovine virus diarrhoea/mucosal disease complex in cattle In Practice 7 195-202

Brownlie J, Clarke MC and Howard CJ (1989) Experimental infection of cattle in early pregnancy with a cytopathic strain of bovine virus diarrhoea virus Research in Veterinary Science 46 307-311

Clarke MC, Brownlie J and Howard CJ (1987) Isolation of cytopathic and non-cytopathic bovine viral diarrhoea virus from infected tissues of infected animals. In Pestivirus Infections of Ruminants pp 3-12 Ed. JW Harkness. Commission of the European Communities, Luxembourg

Collett MS, Moennig V and Horzinek MC (1989) Review article: recent advances in pestivirus research Journal of General Virology 70 253-266

Desport M, Collins ME and Brownlie J (1992) Detection of bovine viral diarrhoea virus nucleic acid by in situ hybridisation. In Proceedings of the Second Symposium on Pestiviruses pp 137-141 Ed. S Edwards. European Society of Veterinary Virology, Annecy

Eyestone WH and First NL (1989) Co-culture of early bovine embryos to the blastocyst stage with oviducal tissue or in conditioned medium Journal of Reproduction and Fertility 85 715-720

Freshney RI (Ed) (1987) Culture of Animal Cells (2nd Edn). Wiley, New York

Guerin B, Chaffaux St, Marquant Le Guienne B, Allietta M and Thibier M (1992) IVF and IV culture of bovine embryos using semen from a bull persistently infected with BVD Theriogenology 37217

Howard CJ, Clarke MC and Brownlie J (1985) An enzyme-linked immunosorbant assay (ELISA) for the detection of antibodies to bovine viral diarrhoea virus (BVDV) in cattle sera Veterinary Microbiology 10 359-369

Howard CJ, Brownlie J and Thomas LH (1986) Prevalence of bovine virus diarrhoea virus viraemia in cattle in the UK Veterinary Record $119628-629$

IETS (1990) Manual of the International Embryo Transfer Society (2nd Edn) Eds DA Stringfellow and SM Seidel. IETS, Champaign, IL

IETS (1992) Conclusions of the research subcommittee of the International Embryo Transfer Society's import/export committee Embryo Transfer Newsletter 10 I4 IETS, Champaign, IL
Kirkland PD, Richards SG, Rothwell JT and Stanley DF (1991) Replication of bovine viral diarrhoea virus in the bovine reproductive tract and excretion of virus in semen during acute and chronic infections Veterinary Record $\mathbf{1 2 8}$ $587-590$

McClurkin AW, Littledike ET, Cutlip RC, Frank GH, Coria MF and Bolin SR (1984) Production of cattle immunotolerant to bovine viral diarrhea virus Canadian Journal of Comparative Medicine 48 156-161

Meyling A (1984) Detection of BVD virus in viremic cattle by an indirect immunoperoxidase technique Current Topics in Veterinary Medicine and Animal Science 29 37-46

Nuttal PA, Luther PD and Stott EJ (1977) Viral contamination of bovine foetal serum and cell cultures Nature $266835-837$

Ohmann HB (1983) Pathogenesis of bovine viral diarrhoea-mucosal disease: distribution and significance of BVDV antigen in diseased calves Research in Veterinary Science 34 5-10

Ohmann HB, Jensen MH, Sorensen KJ and Dalsgaard K (1981) Demonstration of bovine viral diarrhea virus antigen in cryostat- and paraffin-sections of bovine tissues by the immunoperoxidase technique Acta Pathologica et Microbiologica Scandinavica Sect C 89 281-285

Potter ML, Corstvet RE, Looney CR, Fulton RW, Archbald LF and Godke RA (1984) Evaluation of bovine viral diarrhea virus uptake by preimplantation embryos American Journal of Veterinary Research 45 1778-1780

Radostits OM and Littlejohns IR (1988) New concepts in the pathogenesis, diagnosis and control of diseases caused by the bovine viral diarrhea virus Canadian Veterinary Journal 29 513-528

Rall WF and Meyer TK (1989) Zona fracture damage and its avoidance during the cryopreservation of mammalian embryos Theriogenology 31 683-691

Rossi CR, Bridgman CR and Kiesel GK (1980) Viral contamination of bovine fetal lung cultures and bovine fetal serum American Journal of Veterinary Research 41 1680-1681

Singh EL (1985) Disease control: procedures for handling embryos Revue Scientifique et Technologie de l'Office International Des Epizooties 4 867-872

Singh EL, Eaglesome MD, Thomas FC, Papp-vid G and Hare WCD (1982) Embryo transfer as a means of controlling the transmission of viral infections. 1. The in vitro exposure of preimplantation bovine embryos to akabane, bluetongue and bovine viral diarrhea viruses Theriogenology 17 437-444

Ssentongo YK, Johnson RH and Smith JR (1980) Association of bovine viral diarrhoea-mucosal disease virus with ovaritis in cattle Australian Veterinary Journal $56 \quad 272-273$

Straver PJ, Journée DLH and Binkhorst GJ (1983) Neurological disorders, virus persistence and hypomyelination in calves due to intrauterine infections with bovine virus diarrhoea virus. II. Virology and epizootiology Veterinary Quarterly 5 156-164

Voller A and Bidwell DE (1976) Enzyme immunoassays for antibodies in measles, cytomegalovirus infections and after rubella vaccination British Journal of Experimental Pathology 57 243-247

Wentink GH, Aarts T, Mirck MH and van Exsel ACA (1991) Calf born from a persistently infected heifer born after embryo transfer with normal immunity to BVDV Veterinary Record 129 449-450

Zurovac OV, Stringfellow DA, Brock KV, Riddell M and Wright JC (1994) Noncytopathic bovine viral diarrhea virus in a system for in vitro production of bovine embryos Theriogenology 41 841-853 